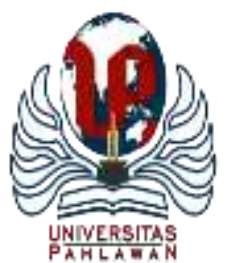

Edukatif : Jurnal Ilmu Pendidikan Volume 4 Nomor 1 Tahun 2022 Halm 240 - 249 EDUKATIF: JURNAL ILMU PENDIDIKAN

Research \& Learning in Education

https:/ledukatif.org/index.php/edukatif/index

\title{
Refleksi Pembelajaran Daring di Universitas Muhammadiyah Kotabumi di Masa Pandemi Covid-19
}

\author{
Karsoni Berta Dinata
}

Universitas Muhammadiyah Kotabumi, Indonesia

E-mail : karsoni.bertadinata@gmail.com

\begin{abstract}
Abstrak
Pandemi Covid-19 berpengaruh signifikan dalam proses pembelajaran di Universitas Muhammadiyah Kotabumi (UMKO). Tujuan dari penelitian ini adalah untuk menilai dan mengamati kembali bagaimana proses pembelajaran daring yang telah dilakukan di Universitas Muhammadaiyah Kotabumi pada masa pandemi (pada semester genap tahun akademik 2019/2020). Untuk mencapai tujuan tersebut, metode penelitian yang dilakukan adalah metode penelitian kuntitatif dengan pendekatan deskriptif. Pengumpulan data dilakukan melalui survei. Berdasarkan hasil penelitian dan pembahasan, kesimpulan yang dapat ditarik untuk senantiasa menjaga dan meningkatkan mutu pembelajaran daring Universitas Muhammadiyah Kotabumi yaitu beberapa aspek yang perlu diperhatikan oleh dosen dalam menjaga mutu pembelajaran daring yaitu, 1) aplikasi pembelajaran yang digunakan harus mudah diakses oleh mahasiswa; 2) dalam perkuliahan online, dosen sebaiknya tidak hanya memberikan materi dalam bentuk $p d f$ atau $p p t$, atau informasi secara teks (deskriftip). Tetapi memberikan juga tutorial dalam perkuliahan online baik secara langsung misalkan menggunakan zoom/ google meet. Bisa juga memberikan tutorial dalam bentuk media misal dengan membagikan video pembelajaran, link youtube, animasi, atau rekam layar; 3) kesesuaian waktu mengajar dengan jadwal perkuliahan; 4) perlu adanya kebijaksanaan dari dosen untuk memberikan tenggang waktu pengumpulan tugas kepada mahasiswa; 5) sebaiknya dosen melaksanakan evaluasi secara objektif dan transparan dengan mengembalikan jawaban dari tugas/ujian mahasiswa.
\end{abstract}

Kata Kunci: Pembelajaran Daring, Covid-19, Zoom.

\begin{abstract}
Covid-19 pandemic has a significant effect on the learning process at the Universitas Muhammadiyah Kotabumi (UMKO). The purpose of this research is to assessment and re-observe how the online learning process has been carried out at the Universitas Muhammadiyah Kotabumi during the pandemic (in the even semester of the 2019/2020 academic year). To achieve this goal, the research method used is a quantitative research method with a descriptive approach. Data collection was carried out through surveys. Based on the results of research and discussion, the conclusions that can be drawn to always maintain and improve the quality of online learning at the Universitas Muhammadiyah Kotabumi are several aspects that need to be considered by lecturers in maintaining the quality of online learning, namely, 1) the learning application used must be easily accessible to students; 2) In online lectures, lecturers should not only provide material in pdf or ppt form, or information in text (descriptive). But also provide tutorials in online lectures either directly, for example using zoom/google meet. You can also provide tutorials in the form of media, for example by sharing learning videos, YouTube links, animations, or recording screens; 3) the suitability of teaching time with lecture schedules; 4) there needs to be a policy from the lecturer to provide a grace period for submitting assignments to students; 5) lecturers should carry out evaluations objectively and transparently by returning answers from student assignments / exams.
\end{abstract}

Keywords: E-learning, Covid-19, Zoom;

Copyright (c) 2022 Karsoni Berta Dinata

$\checkmark$ Corresponding author

Email : karsoni.bertadinata@gmail.com

DOI : https://doi.org/10.31004/edukatif.v4i1.803

ISSN 2656-8063 (Media Cetak)

ISSN 2656-8071 (Media Online)

Edukatif : Jurnal Ilmu Pendidikan Vol 4 No 1 Tahun 2022 p-ISSN 2656-8063 e-ISSN 2656-8071 
241 Refleksi Pembelajaran Daring di Universitas Muhammadiyah Kotabumi di Masa Pandemi Covid-19Karsoni Berta Dinata

DOI: https://doi.org/10.31004/edukatif.v4i1.803

\section{PENDAHULUAN}

Pandemi Covid-19 berpengaruh signifikan dalam proses pembelajaran di Universitas Muhammadiyah Kotabumi. Sebelum pandemi Covid-19, sebagian besar proses pembelajaran dilakukan secara tatap muka langsung, meskipun ada juga yang melakukan proses pembelajaran secara blended learning walau dalam porsi yang sedikit. Terhitung sejak dikeluarkannya kebijakan kampus agar mahasiswa belajar dari rumah, maka secara otomatis proses pembelajaran harus dilaksanakan secara online (daring).

Untuk menjaga mutu proses pembelajaran daring di universitas Muhammadiyah Kotabumi, beberapa kebijakan telah diambil oleh pimpinan Universitas Muhammadiyah Kotabumi diantaranya membagikan paket kuota internet kepada mahasiswa. Tentu saja pembagian kuota kepada mahasiswa bertujuan untuk mendukung kelancaran proses pembelajaran daring.

Pembelajaran daring dapat diartikan sebagai pembelajaran yang dilaksanakan dengan memanfaatkan jaringan internet. Pembelajaran daring sangat cocok dilaksanakan dimasa pandemi Covid-19 karena pembelajaran tetap berlangsung walaupun tanpa harus tatap muka langsung. Beberapa aplikasi yang bisa digunakan dalam pembelajaran daring yaitu Google Classroom, Zoom, Whatsap, Edmodo, Ed-link dan lainlain. Persentase Aplikasi yang digunakan dalam pembelajaran daring dapat dilihat pada grafik berikut (Ningsih, 2020).

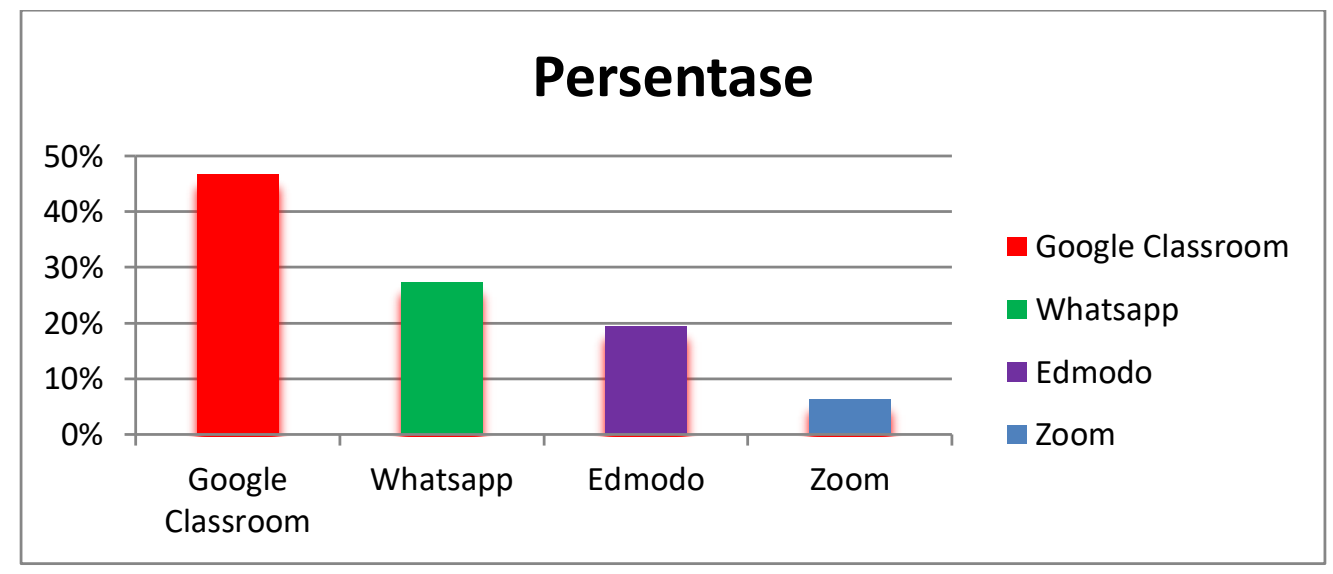

Grafik 1. Penggunaan Aplikasi Pembelajaran Daring

Di Universitas Muhammadiyah Kotabumi, beberapa aplikasi yang digunakan oleh dosen dalam pembelajaran daring yaitu Google Classroom, Whatsap Group, Zoom, Gmail, Ed-link, dan Siakad. Pandemi Covid-19 yang mengakibatkan perubahan yang signifikan dalam proses pembelajaran. Dosen yang telah terbiasa melaksanakan pembelajaran secara tatap muka langsung, harus mengubah proses pembelajarannya secara daring. Tentu saja, perubahan proses pembelajaran dari tatap muka langsung menjadi daring, menuntut dosen dan mahasiswa mampu beradaptasi dengan perubahan ini.

Beberapa indikator dapat dijadikan acuan sebagai faktor pendukung keberhasilan pembelajaran daring. Keberhasilan pembelajaran daring sangat tergantung dari beberapa faktor seperti kemampuan peserta didik dalam menggunakan IT, tujuan pembelajaran, sarana prasarana yang dimiliki dan lain sebagainya (Carbonell, K. B., Dailey-Hebert, A., \& Gijselaers, 2013), manajemen pembelajaran (Zunaika, 2020), "Mahasiswa memiliki handphone, kuota dan jaringan internet yang stabil" (Putria, H., Maula, L. H., \& Uswatun, 2020), kesiapan dosen dan mahasiswa dalam pembelajaran daring (Budhianto, 2020) dan dukungan dari dari keluarga (Lailatussaadah et al., 2020), Selain itu juga perlu adanya kerjasama antara pihak guru, siswa, dan orang tua dalam menunjang keberhasilan pembelajaran daring (A. Dewi, 2020). 
Oleh karena itu untuk melihat efektifitas suatu pembelajaran daring dapat ditinjau dari pencapaian indikator pendukung keberhasilan pembelajaran daring. Indikator tersebut yaitu 1) Sarana Prasarana Pembelajaran daring, 2) Manajemen pendidikan, 3) Kesiapan dosen dan mahasiswa, dan 4) Dukungan dari keluarga.

Penelitian berkaitan dengan pembelajaran dimasa pandemi Covid-19 telah banyak dilakukan oleh berbagai peneliti di berbagai tempat. Penelitian itu diantaranya yaitu (Wulandari \& Purwanta, 2021) meneliti di surakarta pada jenjang pendidikan TK; (Hamdani \& Priatna, 2020) yang meneliti di Kabupaten Subang pada jenjang SD ; (Putria et al., 2020) meneliti di Sukabumi pada jenjang SD. Di Universitas Muhammadiyah Kotabumi, hanya ada satu penelitian terkait pembelajaran daring di masa pandemi yaitu penelitian yang dilakukan oleh (Dinata, 2020) yang meneliti di Program Studi pendidikan Matematika pada mata kuliah Geometri Transformasi. Oleh karena itu hasil penelitian ini dilakukan untuk melengkapi penelitian dengan meneliti pada lingkup yang lebih luas yaitu di Universitas muhammadiyah Kotabumi.

Penelitian ini telah dilakukan di Universitas Muhammadadiyah Kotabumi pada bulan Juli 2020. Tujuan dari penelitian ini adalah untuk menilai dan mengamati kembali bagaimana proses pembelajaran daring yang telah dilakukan di Universitas Muhammadaiyah Kotabumi pada masa pandemi (pada semester genap tahun akademik 2019/2020).

\section{METODE PENELITIAN}

Tujuan dari penelitian ini adalah untuk menilai dan mengamati kembali bagaimana proses pembelajaran daring yang telah dilakukan di Universitas Muhammadaiyah Kotabumi pada masa pandemi (pada semester genap tahun akademik 2019/2020). Untuk mencapai tujuan tersebut, metode penelitian yang dilakukan adalah metode penelitian kuntitatif dengan pendekatan deskriptif. Pengumpulan data dilakukan melalui survei. Teknik survei digunakan untuk mengumpulkan informasi dari sejumlah orang mengenai suatu topik atau isu tertentu (Gunawan, 2017). Hasil survei disampaikan dalam Rapat Tinjauan Manamen yang dihadiri oleh pimpinan, dosen, dan perwakilan mahasiswa. Hasil rapat ditulis sebagai deskripsi evaluasi internal.

Instrumen yang digunakan adalah angket. Angket terdiri dari 9 butir pertanyaan tertutup dan 1 butir pertanyaan terbuka. Angket didistribusikan melalui siakad Universitas Muhammadiyah Kotabumi. Adapun Responden yang mengembalikan isian angket sebanyak 1287 responden. Adapun rincian jumlah responden berdasarkan prodi dapat dilihat pada gambar berikut.

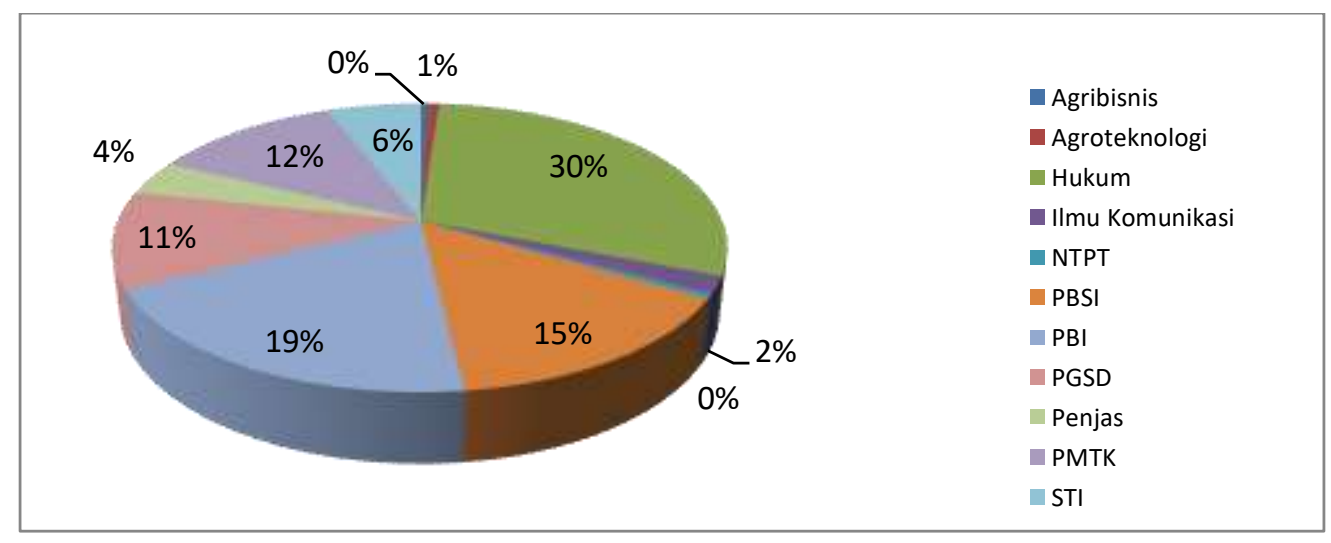

Gambar 1. Profil Responden Penelitian 
243 Refleksi Pembelajaran Daring di Universitas Muhammadiyah Kotabumi di Masa Pandemi Covid-19Karsoni Berta Dinata

DOI: https://doi.org/10.31004/edukatif.v4i1.803

\section{HASIL DAN PEMBAHASAN PENELITIAN}

Alat pengumpul data data dalam penelitian ini adalah Angket. Angket dikembangkan berdasarkan indikator pendukung keberhasilan pembelajaran daring. Penjelasannya adalah sebagai berikut.

\section{a) Sarana Prasarana Pembelajaran daring}

Dari indikator sarana dan prasarana pembelajaran daring diturunkan beberapa butir pertanyan yaitu: 1) Dosen menggunakan aplikasi perkuliahan online yang mudah diakses, 2) Biaya (kuota internet) yang digunakan untuk kuliah online relatif mahal.

\section{b) Manajemen Pendidikan.}

Selanjutnya, untuk indikator Manajemen pendidikan diturunkan beberapan butir pertanyaan yaitu; 1) Dosen memberikan tutorial dalam perkuliahan online, 2) informasi terkait perkuliahan disampaikan melalui aplikasi, 3) Dosen memberikan kesempatan tenggang waktu untuk mahasiswa mengumpulkan tugas online, 4) Dosen melakukan evaluasi pembelajaran daring secara objektif dan transparan.

\section{c) Kesiapan dosen dan mahasiswa,}

Dari indikator kesiapan dosen dan mahasiwa diturunkan beberapa butir pertanyaan yaitu; 1) Dosen memberikan silabus, RPS, dan materi secara online, 2) dosen mengajar sesuai dengan jadwal perkuliahan.

\section{d) Dukungan dari keluarga}

Dari indikator dukungan dari keluarga diturunkan beberapa butir pertanyaan yaitu; dukungan keluarga sangat mendukung saya untuk belajar secara daring.

Data hasil penelitian selanjutnya akan disajikan dalam bentuk diagram lingkaran, kemudian dianalisis secara deskrifip berdasarkan data .

Analisis hasil penelitian diuraikan berdasarkan masing-masing pertanyaan pada angket. Selanjutnya diuraikan penjelasan terkait data yang disajikan, interpretasi hambatan/permasalahan berdasarkan evaluasi internal dan tindak lanjut/rekomendasi pembelajaran kedepan. Berikut penjelasannya.

Pernyataan pertama yaitu dosen menggunakan aplikasi perkuliahan online yang mudah diakses. Hasil responden terkait Pernyataan tersebut disajikan dalam diagram berikut.

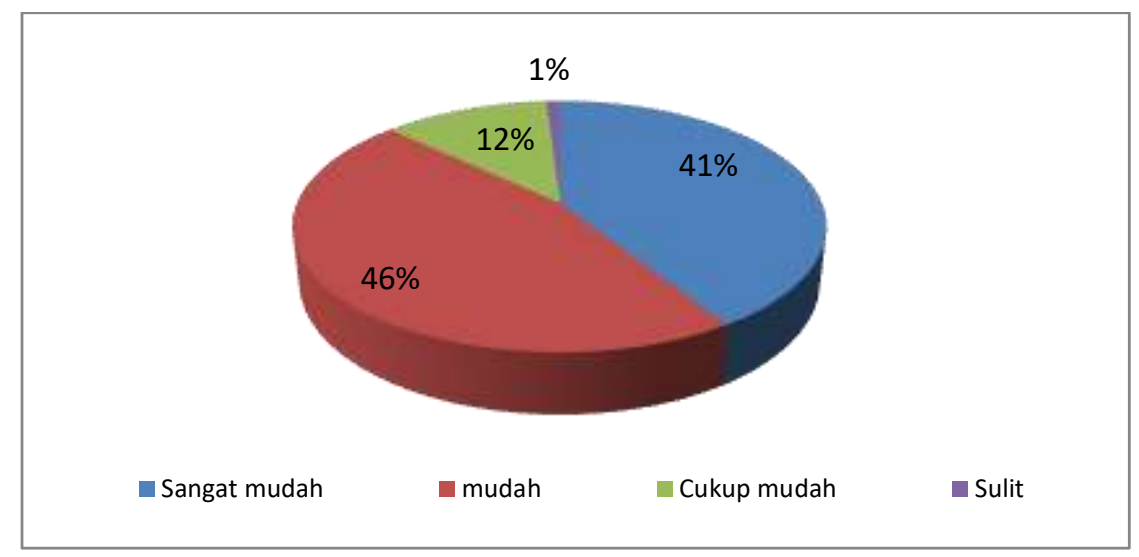

Gambar 2. Kemudahan akses

Berdasarkan gambar 2 dapat dikatakan bahwa aplikasi perkuliahan online yang digunakan oleh dosen di Universitas Muhammadiyah Kotabumi mudah diakses oleh mahasiswa. berdasarkan hasil evaluasi internal di Universitas Muhammadiyah Kotabumi, aplikasi yang digunakan dalam perkuliahan online adalah Whatsap, 
G-mail, Zoom, Ed-Link, Google Meet, dan Siakad. Menurut mahasiswa, aplikasi pembelajaran tersebut mudah digunakan dan kompatibel dengan hampir semua jenis android yang digunakan oleh mahasiswa.

Meskipun berdasarkan hasil penelitian yang dilakukan oleh Jamaludin et al (2020) yang menyatakan "bahwa lebih dari 60\% mahasiswa di UIN Sunan Gunung Djati mayoritas ( $>60 \%$ ) menggunakan Google Classroom", akan tetapi Dosen di Universitas Muhammadiyah Kotabumi jarang bahkan tidak ada yang menggunakan Google Classrom. Hal ini dikarenakan Universitas Muhammadiyah Kotabumi telah memfasilitasi dengan aplikasi pembelajaran daring yaitu Edlink yang terintegrasi dengan siakad sehingga memudahkan dosen dalam hal jadwal mata kuliah; presensi; pemberian materi, tugas, dan ujian; dan pengumpulan tugas.

Pernyataan kedua yaitu pemberian tutorial dalam perkuliahan online. Dasar memberikan pertanyaan tersebut adalah dari hasil penelitian oleh (I. S. Dewi \& Sudarwanto, 2020) menyatakan bahwa "pemberian tutorial (baik secara langsung atau melalui media) dalam perkuliahan online memudahkan guru dalam penyampaian materi atau tugas dan juga memudahkan siswa dalam memahami materi atau tugas". Jawaban dari responden terkait Pernyataan tersebut disajikan dalam diagram lingkaran berikut.

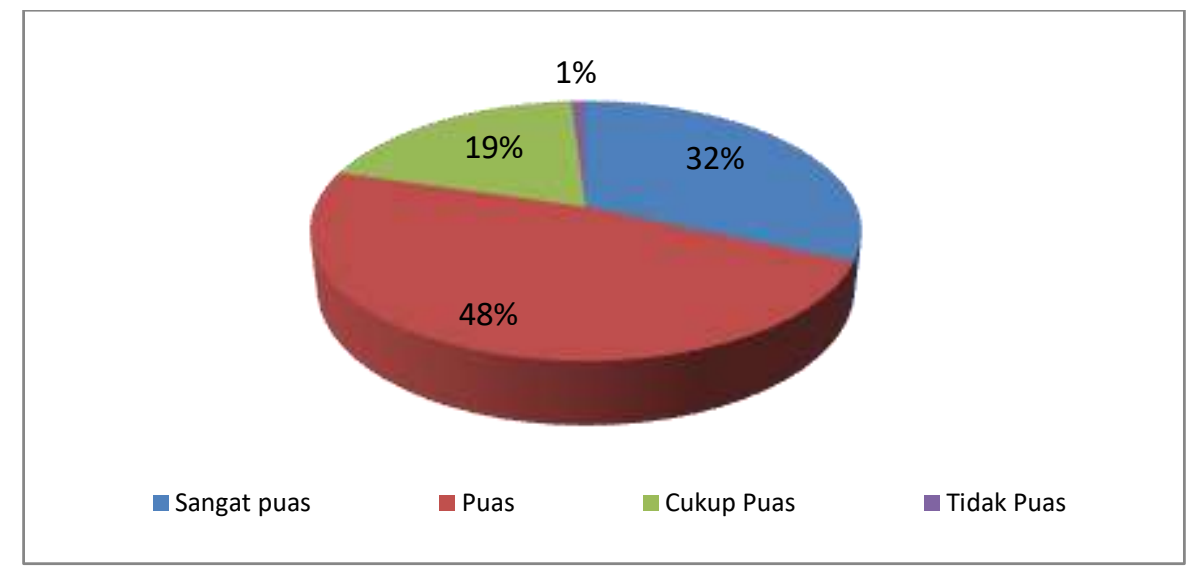

Gambar 3. Pemberian Tutorial

Berdasarkan Gambar 3, cukup banyak mahasiswa yang puas dengan tutorial yang diberikan oleh dosen, namun jika diperhatikan masih ada yang merasa cukup puas bahkan tidak puas dengan pemberian tutorial oleh dosen dalam perkuliahan online.

Hasil penelitian yang dilakukan oleh (Priyanda, 2019) menyatakan bahwa "adanya tutorial dalam perkuliahan online mengakibatkan terjadinya interaksi anatara guru dan siswa berakibat pada tercapainya tujuan pembelajaran yang signifikan". Oleh karena itu, pemberian tutorial dalam perkuliahan online sangat efektif dalam mencapai tujuan pembelajaran. Dengan demikian disimpulkan bahwa sangat disarankan pendidik (dosen) dalam perkuliahan online tidak hanya memberikan materi dalam bentuk $p d f$ atau $p p t$, atau informasi secara teks (deskriftif). Tetapi memberikan juga tutorial dalam perkuliahan online baik secara langsung misalkan menggunakan zoom/ google meet. Bisa juga memberikan tutorial dalam bentuk media misal dengan membagikan video pembelajaran, link Youtube, Animasi, atau rekam layar.

Pernyataan ketiga yaitu informasi perkuliahan disampaikan melalui aplikasi. Pemberian pertanyaan ini dilakukan karena mengingat perkuliahan yang dilaksanakan secara daring, maka pemberian informasi tidak bisa dilakukan secara langsung dalam tatap muka di kelas. Sehingga jika dosen ingin memberikan informasi terkait perkuliahan, maka diharapkan semua mahasiswa mengetahui informasi tersebut. Hal ini dapat dilakukan dengan memberikan informasi perkuliahan melalui aplikasi misal Whatsap Group, Edlink, dan Siakad. Pemberian informasi perkuliahan melalui telpon, menchat langsung (japri), dan gmail agar disebarluaskan kepada mahasiswa yang lain dinilai akan berpotensi adanya mahasiswa yang tidak mengetahui 
245 Refleksi Pembelajaran Daring di Universitas Muhammadiyah Kotabumi di Masa Pandemi Covid-19Karsoni Berta Dinata

DOI: https://doi.org/10.31004/edukatif.v4i1.803

informasi tersebut. Berdasarkan jawaban responden terkait Pernyataan tersebut, disajikan dalam diagram lingkaran berikut.

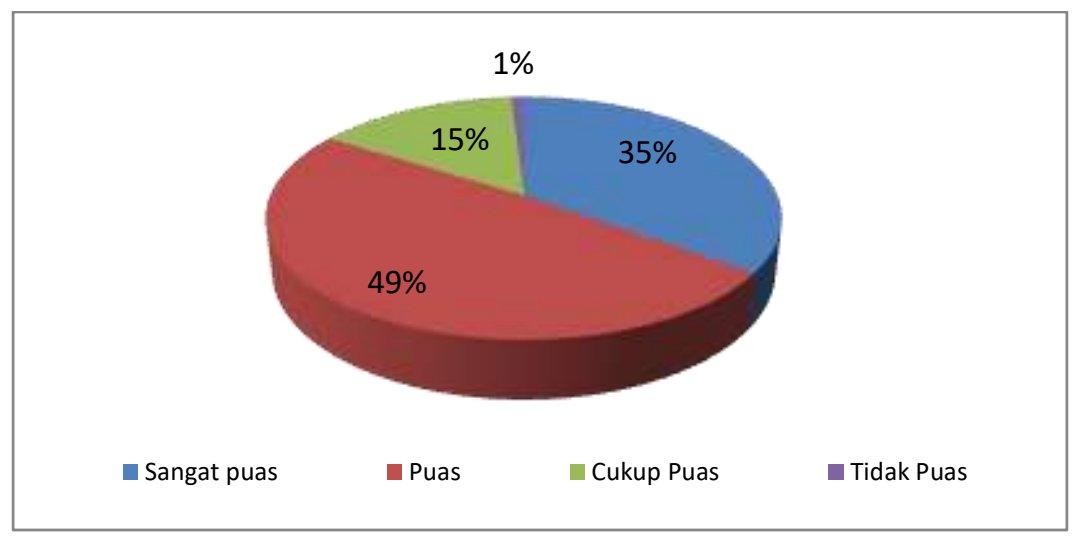

Gambar 4. Cara Pemberian Informasi Perkuliahan

Berdasarkan Gambar 4, cukup banyak mahasiswa yang puas dengan cara pemberian informasi perkuliahan oleh dosen, namun jika diperhatikan masih ada sejumlah mahasiswa yang cukup puas dan tidak puas dengan cara pemberian informasi perkuliahan oleh dosen. Dengan demikian disarankan agar dalam pemberian informasi perkuliahan disampaikan melalui aplikasi seperti Whatsap Group, atau Edlink, atau Siakad.

Pernyataan ke empat yaitu Silabus, RPS, dan Materi yang diberikan oleh dosen secara daring. Butir ini ditanyakan kepada mahasiswa dikarenakan mengingat dalam pembelajaran daring mahasiswa dituntut untuk belajar secara mandiri, sehingga dosen perlu memberikan silabus serta RPS bahkan materi agar mampu menuntun mahasiswa terkait apa dan bagaimana perkuliahan diselenggarakan. Jawaban responden dari pernyataan tersebut disajikan dalam diagram lingkaran berikut.

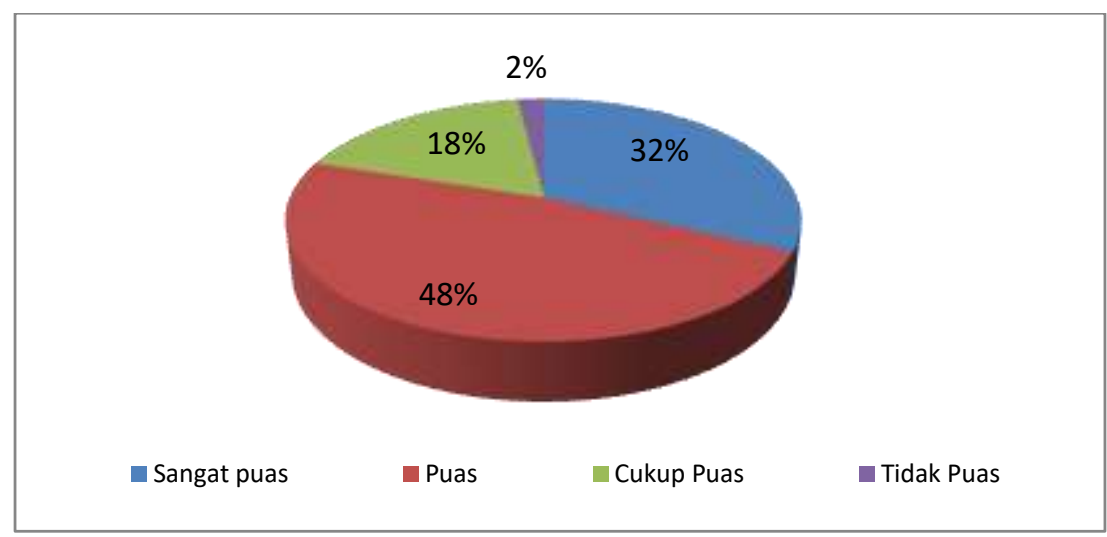

Gambar 5. Pemberian silabus, RPS, dan Materi

Berdasarkan Gambar 5, mayoritas responden sangat puas dan puas dengan silabus, RPS, dan Materi yang diberikan oleh Dosen, namun perlu diperhatikan masih ada mahasiswa yang cukup puas bahkan tidak puas dengan Silabus, RPS, dan Materi yang disampaikan oleh dosen. Berdasarkan evaluasi internal, Ketdakpuasan mahasiswa terhadap silabus, RPS, dan materi yang disampaikan oleh dosen disebabkan masih ada beberapa dosen yang tidak mengupload Silabus, RPS, ataupun materi dalam Siakad Universitas Muhammadiyah atau membagikan lewat media sosial online. Selain itu, ketidak puasan mahasiswa juga 
246 Refleksi Pembelajaran Daring di Universitas Muhammadiyah Kotabumi di Masa Pandemi Covid-19Karsoni Berta Dinata

DOI: https://doi.org/10.31004/edukatif.v4i1.803

disebabkan karena mahasiswa cenderung tidak tertarik dengan materi yang dibagikan dalam bentuk ppt atau $p d f$. Mahasiswa lebih menyukai materi perkuliahan dalam bentuk tutorial atau video pembelajaran.

Harus diakui bahwa selama mahasiswa melaksanakan pembelajaran daring, tugas yang diberikan oleh dosen sangat padat dan cukup membebani mahasiswa. Oleh karena itu, pernyataan butir ke-lima dari angket ini yaitu dosen memberikan kesempatan tenggang waktu untuk mahasiswa mengumpulkan tugas online. Jawaban responden dari pernyataan tersebut disajikan dalam diagram lingkaran berikut.

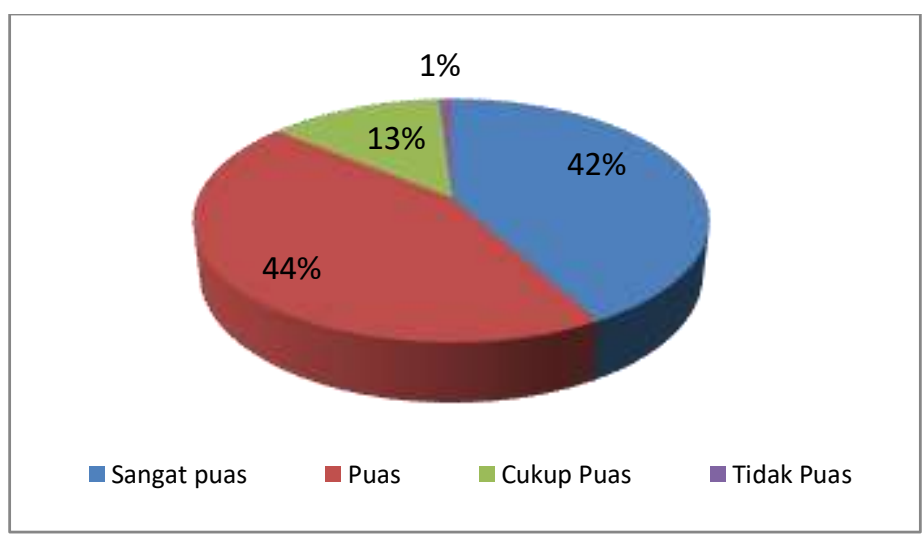

Gambar 6. Pemberian kesempatan tenggang waktu pengumpulan tugas.

Berdasarkan gambar 6, mayoritas responden sangat puas, puas, dan cukup puas dengan pemberian tenggang waktu pengumpulan tugas, tetapi masih ada yaitu sebanyak $1 \%$ dari responden yang menyatakan tidak puas dengan pemberian kesempatan tenggang waktu pengumpulan tugas. Mengingat tugas perkuliahan yang harus diselesaikan oleh mahasiswa cukup banyak, perlu adanya kebijaksanaan dari dosen untuk memberikan tenggang waktu pengumpulan tugas kepada mahasiswa.

Pernyataan ke enam yaitu Dosen mengajar online sesuai jadwal perkuliahan. Jawaban responden dari pernyataan ini disajikan dalam diagram lingkaran berikut.

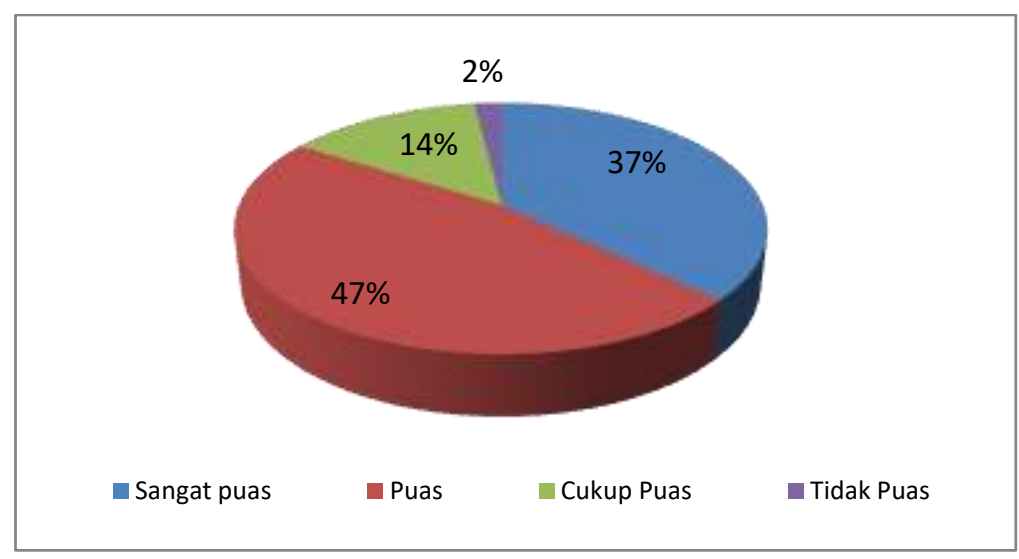

Gambar 7. Dosen mengajar Sesuai jadwal

Berdasarkan Gambar 7, mayoritas responden sangat puas dan puas dengan ketepatan waktu mengajar dosen, tetapi masih ada responden yang cukup puas bahkan tidak puas dengan ketepatan waktu mengajar dosen. Berdasarkan evaluasi internal, dosen kadang-kadang lupa dengan jadwal mengajarnya. Oleh kerena itu perlu ada strategi agar pembelajaran online berjalan sesuai dengan jadwal. Beberapa Cara yang bisa ditempuh yaitu 1) meminta kepada mahasiswa mengingatkan ketika pembelajaran akan dimulai, 2) dosen mendownload 
247 Refleksi Pembelajaran Daring di Universitas Muhammadiyah Kotabumi di Masa Pandemi Covid-19Karsoni Berta Dinata

DOI: https://doi.org/10.31004/edukatif.v4i1.803

aplikasi siakad cloud sebagai pengingat dan dapat digunakan di Universitas Muhammadiyah, sehingga pembelajaran bisa dimulai kapanpun dan dimanapun.

Pertanyaan ketujuh yaitu apakah dalam dalam sistem daring anda merasa optimal belajar dirumah. Jawaban dari responden terkait pertanyaan tersebut disajikan dalam diagram lingkaran berikut.

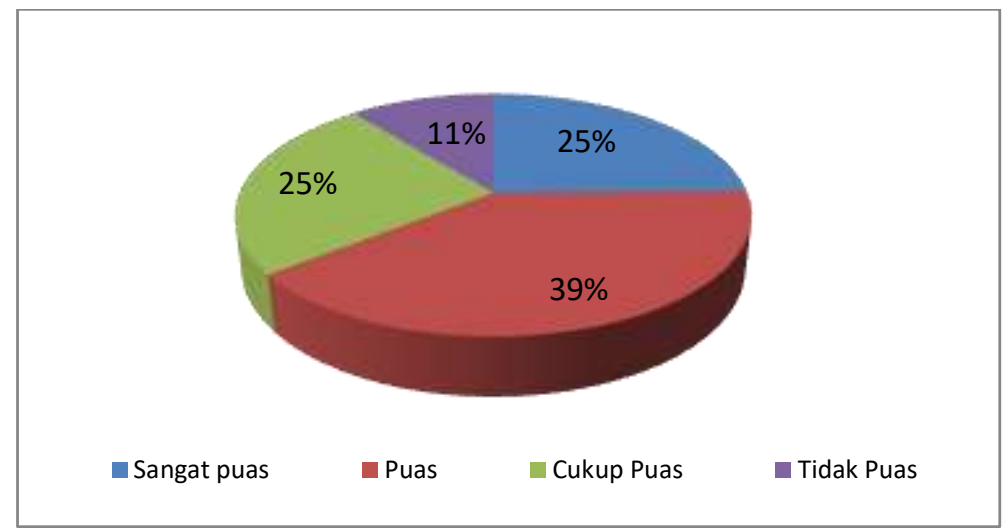

\section{Gambar 8. Tanggapan responden terhadap optimalitas belajar secara daring}

Berdasarkan Gambar 8, dapat disimpulkan bahwa cukup banyak responden yang merasa cukup dan tidak puas (optimal) belajar secara daring di rumah. Berdasarkan evaluasi internal, diperoleh bahwa mahasiswa merasa lebih optimal belajar tatap muka langsung dikelas dari pada belajar daring di rumah. Siswa merasa bosan karena tidak bertemu dengan teman dan gurunya secara langsung (Yunitasari \& Hanifah, 2020).

Pertanyaan ke-delapan yaitu evaluasi yang dilakukan oleh dosen selama pembelajaran daring dilaksanakan secara objektif dan transparan. Jawaban responden terkait pernyataan tersebut disajikan dalam diagram lingkaran berikut.

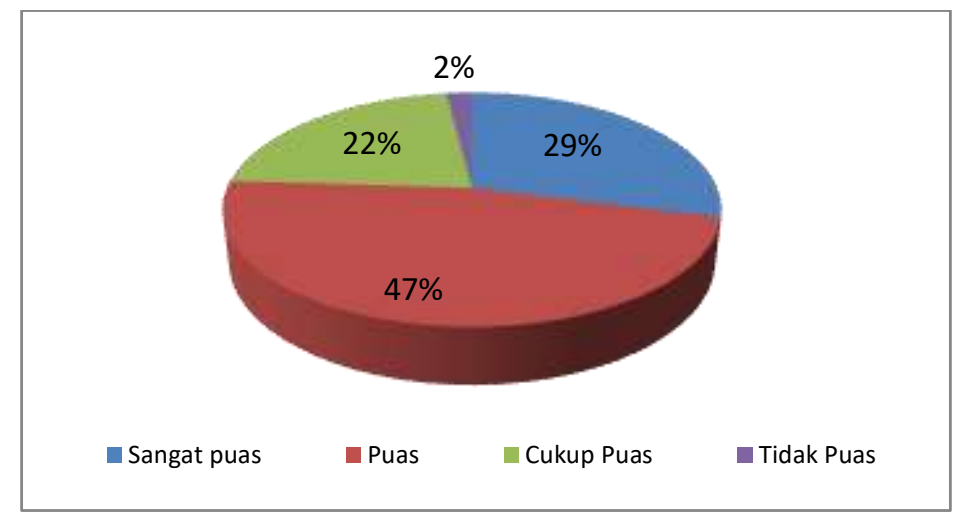

Gambar 9. Objektifitas dan Transparansi evaluasi pembelajaran.

Berdasarkan Gambar 9, dapat dikatakan bahwa hampir seper-empat dari responden merasa cukup puas dan tidak puas dengan evaluasi (penilaian) yang dilakukan oleh dosen. Berdasarkan evaluasi internal, diperoleh informasi bahwa banyak dosen yang tidak mengembalikan hasil ujian/tugas mahasiswa. olehkarena itu sebaiknya dosen melaksanakan evaluasi secara objektif dan transparan dengan mengembalikan jawaban dari tugas/ujian mahasiswa.a Tentu saja tugas dan ujian tersebut telah dikoreksi dan dinilai oleh dosen .

Pernyataan terkahir berkaitan dengan biaya perkuliahan online. Pernyataan butir kesembilan yaitu biaya (kuota internet) yang digunakan untuk perkuliahan online relativ mahal. Jawaban responden terkait pernyataan tersebut disajikan dalam diagram lingkaran berikut. 


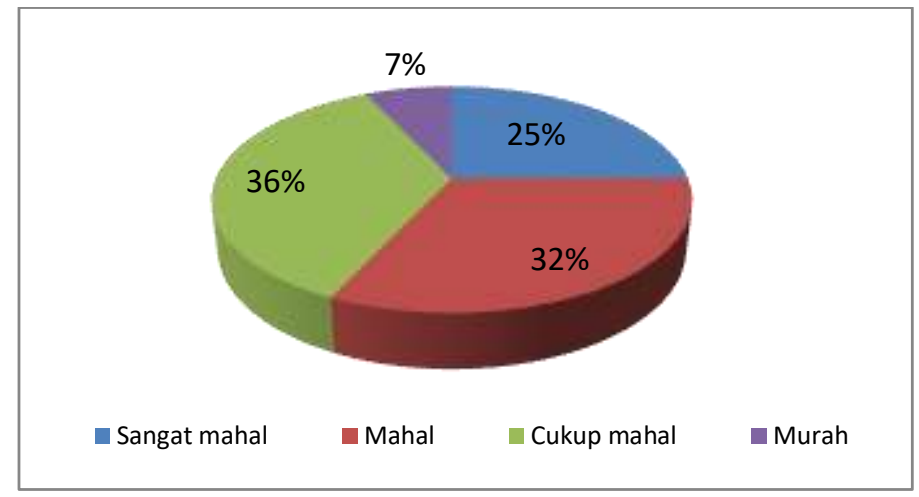

Gambar 10. Biaya Perkuliahan online

Berdasarkan gambar 10, mayoritas responden mengaku bahwa biaya perkuliahan online mahal. Hal ini wajar mengingat mahasiswa mesti selalu online selama pembelajaran daring dengan menggunakan aplikasi pembelajran daring apapun. Berdasarkan hasil evaluasi internal, diperoleh mahasiswa cukup terbantu dengan bantuan kuota dari kampus. Mengingat saat ini semua mahasiswa Universitas Muhammadiyah Kotabumi telah mendapatkan bantuan kuota dari pemerintah, diharapkan kedepan kendala terkait biaya perkuliahan bukan masalah lagi.

Penelitian yang berkaitan dengan pelaksanaan pembelajaran daring di masa pandemi Covid-19 menyebutkan bahwa efektivitas Pembelajaran daring memerlukan biaya kuota, oleh karena itu perlu adanya kebijakan mengenai biaya pembelajaran daring (Yudiawan, 2020), Selain itu penelitian lain menyebutkan bahwa kelemahan pembelajaran daring melalui zoom adalah kurang fokus karena pembelajaran dilakukan dari rumah, karena koneksi terputus karena sinyal buruk, dan tidak ada pengawasan langsung dari dosen (Syswianti, 2020). Penelitian yang telah dilakukan tersebut mengkaji secara khusus kelemahan dari pembelajaran daring belum ada kajian secara menyeluruh terkait evaluasi pembelajaran daring, oleh karena itu penelitian ini dilakukan secara komprehenship mengevaluasi pembelajaran daring dari berbagai aspek.

\section{KESIMPULAN}

Berdasarkan hasil penelitian dan pembahasan kesimpulan yang dapat ditarik yaitu sebagai berikut. 1) Aplikasi yang biasa digunakan dalam pembelajaran daring seperti Whatsap, G-mail, Zoom, Ed-Link, Google Meet, dan Siakad cukup mudah diakses oleh mahasiswa; 2) Sangat disarankan pendidik (dosen) dalam perkuliahan online tidak hanya memberikan materi dalam bentuk $p d f$ atau $p p t$, atau informasi secara teks (deskriftif). Tetapi memberikan juga tutorial dalam perkuliahan online baik secara langsung misalkan menggunakan zoom/ google meet. Bisa juga memberikan tutorial dalam bentuk media misal dengan membagikan video pembelajaran, link Youtube, Animasi, atau rekam layar; 3) Strategi agar pembelajaran daring berjalan sesuai dengan jadwal. Beberapa Cara yang bisa ditempuh yaitu 1) meminta kepada mahasiswa mengingatkan ketika pembelajaran akan dimulai, 2) dosen mendownload aplikasi siakad cloud sebagai pengingat dan dapat digunakan di Universitas Muhammadiyah, sehingga pembelajaran bisa dimulai kapanpun dan dimanapun; 4) Mengingat tugas perkuliahan yang harus diselesaikan oleh mahasiswa cukup banyak, perlu adanya kebijaksanaan dari dosen untuk memberikan tenggang waktu pengumpulan tugas kepada mahasiswa.

\section{DAFTAR PUSTAKA}

Budhianto, B. (2020). Analisis Perkembangan Dan Faktor Yang Mempengaruhi Keberhasilan Pembelajaran Daring (E-Learning ). Jurnal Agriwidya, 1(1), 11-29. 
249 Refleksi Pembelajaran Daring di Universitas Muhammadiyah Kotabumi di Masa Pandemi Covid-19Karsoni Berta Dinata

DOI: https://doi.org/10.31004/edukatif.v4i1.803

Carbonell, K. B., Dailey-Hebert, A., \& Gijselaers, W. (2013). Unleashing The Creative Potential Of Faculty To Create Blended Learning. The Internet And Higher Education, 18(1), 29-37.

Dewi, A. (2020). Dampak Covid-19 Terhadap Covid-19 Terhadap Implementasi Pembelajaran Daring Di Sekolah Dasar. Edukatif: Jurnal Ilmu Pendidikan, 2(1), 55-61.

Dewi, I. S., \& Sudarwanto, T. (2020). Pengembangan Media Pembelajaran Video Tutorial Pada Mata Pelajaran Komunikasi Bisnis Materi Prosedur Interview Bisnis Daring Dan Pemasaran Smk Negeri 2 Blitar. Jurnal Pendidikan Tata Niaga (Jptn), 8(1), 737-743.

Dinata, K. B. (2020). View Of Problematika Pembelajaran Daring Mata Kuliah Geometri Transformasi Di Masa Pandemi Covid-19. Eksponen, 10(2), 50-58. Https://Jurnal.Umko.Ac.Id/Index.Php/Eksponen/Article/View/296/165

Gunawan, H. (2017). Dasar-Dasar Metodologi Penelitian Pendidikan. Fakultas Tarbiyah Dan Keguruan Uin Sunan Gunung Djati.

Hamdani, A., \& Priatna, A. (2020). Efektifitas Implementasi Pembelajaran Daring (Full Online) Dimasa Pandemi Covid- 19 Pada Jenjang Sekolah Dasar Di Kabupaten Subang. Didaktik: Jurnal Ilmiah Pgsd Stkip Subang, 6(1), 1-9. Https://Doi.Org/10.36989/Didaktik.V6i1.120

Lailatussaadah, Fitriyawany, F., Erfiati, E., \& Mutia, S. (2020). Faktor-Faktor Penunjang Dan Penghambat Dalam Pelaksanaan Pembelajaran Daring (Online) Ppg Dalam Jabatan (Daljab) Pada Guru Perempuan Di Aceh. Gender Equality: International Journal Of Child And Gender Studies, 6(2), 41. Https://Doi.Org/10.22373/Equality.V6i2.7735

Ningsih, S. (2020). Persepsi Mahasiswa Terhadap Pembelajaran Daring Pada Masa Pandemi Covid-19. Jinotep (Jurnal Inovasi Dan Teknologi Pembelajaran): Kajian Dan Riset Dalam Teknologi Pembelajaran, 7(2), 124-132. Https://Doi.Org/10.17977/Um031v7i22020p124

Priyanda, R. (2019). Efektivitas Penggunaan Media Pembelajaran Matematika Menggunakan Media Cai Dengan Tipe Tutorial Terhadap Hasil Belajar Siswa Smk Muhammadiyah 9 Medan Effectivenes Of Using Mathematics Learning Using Cai With Tutorial Type Towards Learning Results Senior H. Nomor, $50-57$.

Putria, H., Maula, L. H., \& Uswatun, D. A. (2020). Analisis Proses Pembelajaran Dalam Jaringan (Daring) Masa Pandemi Covid-19 Pada Guru Sekolah Dasar. Jurnal Basicedu, 4(4), 861-872. Https://Doi.Org/10.31004/Basicedu.V4i4.460

Putria, H., Maula, L. H., \& Uswatun, D. A. (2020). Analisis Proses Pembelajaran Dalam Jaringan (Daring) Masa Pandemi Covid- 19 Pada Guru Sekolah Dasar. Jurnal Basicedu, 4(4), 861-870. Https://Doi.Org/10.31004/Basicedu.V4i4.460

Wulandari, H., \& Purwanta, E. (2021). Jurnal Obsesi : Jurnal Pendidikan Anak Usia Dini Pencapaian Perkembangan Anak Usia Dini Di Tk Selama Pembelajaran Daring Saat Pandemi Covid-19 Abstrak. Jurnal Obsesi, 5(1), 452-462. Https://Doi.Org/10.31004/Obsesi.V5i1.626

Yudiawan, A. (2020). Belajar Bersama Covid 19: Evaluasi Pembelajaran Daring Era Pandemi Di Perguruan Tinggi Keagamaan Islam Negeri, Papua Barat. Al-Fikr: Jurnal Pendidikan Islam, 6(1), 10-16. Https://Doi.Org/10.32489/Alfikr.V6i1.64

Yunitasari, R., \& Hanifah, U. (2020). Pengaruh Pembelajaran Daring Terhadap Minat Belajar Siswa Pada Masa Covid 19. Edukatif: Jurnal Ilmu Pendidikan, 2(3), 232-243. Https://Doi.Org/10.31004/Edukatif.V2i3.142

Syswianti, Desy, Naning Suryani, And Tri Wahyuni. "Evaluasi Pembelajaran Daring Dengan Menggunakan Aplikasi Zoom Di Masa Pendemi Covid-19 Pada Mata Kuliah Pengantar Asuhan Kebidanan." Jurnal Medika Cendikia 7.1 (2020): 40-50.

Zunaika, G. A. (2020). Implementasi Pembelajaran Daring Di Madrasah Ibtidaiyah Study Pada Guru Mi Istiqomah Ma'arif Nu Mojokerto Kabupaten Sragen Tahun Pelajaran 2019/2020. Iain Salatiga. 